FERNANDES DE AQUINO, Sérgio Ricardo; DOS SANTOS, Wagner; FICAGNA, Victoria. Ética, moral e amizade em tempos líquidos: fundamentos críticos para uma práxis de direitos humanos. Revista Eletrônica Direito e Política, Programa de Pós-Graduação Stricto Sensu em Ciência Jurídica da UNIVALI, Itajaí, v.14, n.1, $1^{\circ}$ quadrimestre de 2019. Disponível em: www.univali.br/direitoepolitica - ISSN 1980-7791

\title{
ÉTICA, MORAL E AMIZADE EM TEMPOS LÍQUIDOS: FUNDAMENTOS CRÍTICOS PARA UMA PRÁXIS DE DIREITOS HUMANOS
}

\author{
ETHICS, MORAL AND FRIENDSHIP IN LIQUID TIMES: CRITICAL ARGUMENTS
}

FOR A PRAXIS OF HUMAN RIGHTS

\author{
Sérgio Ricardo Fernandes de Aquino ${ }^{1}$ \\ Wagner dos Santos ${ }^{2}$ \\ Victoria Ficagna ${ }^{3}$
}

\section{RESUMO}

A caracterização do momento presente como "tempo líquido" mostra a amplitude das comunicações humanas e, ao mesmo tempo, a fragilidade e o esvaziamento das relações humanas. Valores como a Ética, Moral, Amizade e Fraternidade são considerados descartáveis, já que nada, hoje, foi feito para durar, ou, numa expressão, não se deseja hipotecar o futuro. Por esse motivo, o objetivo geral deste estudo é analisar se Ética, Moral, Amizade e Fraternidade são, ainda, vetores indispensáveis para a constituição das relações humanas nesse tempo líquido. 0 método de investigação escolhido é o Dedutivo. Percebe-se, como parte das conclusões, que a práxis das relações humanas não pode se desenvolver sob as premissas axiológicas vazias de um tempo líquido, mas necessitam, ainda, dessa

\footnotetext{
1 Doutor e Mestre em Ciência Jurídica pela Universidade do Vale do Itajaí - UNIVALI. Professor Permanente do Programa de Pós-Graduação Stricto Sensu - Mestrado - em Direito da Faculdade Meridional - IMED. Pesquisador da Faculdade Meridional. Membro do Grupo de Estudos Interdisciplinares em Ciências Humanas, Contingência e Técnica na linha de pesquisa Norma, Sustentabilidade e Cidadania da Universidade Federal do Maranhão - UFMA. Membro associado do Conselho Nacional de Pós-Graduação em Direito - CONPEDI. Coordenador do Grupo de Pesquisa em Ética, Cidadania e Sustentabilidade no Programa de Mestrado em Direito (PPGD) da Faculdade Meridional - IMED. Membro do Grupo de Pesquisa sobre Direitos Culturais e Pluralismo Jurídico da Faculdade Meridional - IMED. Membro do Grupo de Pesquisa sobre Transnacionalismo e Circulação de Modelos Jurídicos da Faculdade Meridional - IMED. Vice-líder no Centro Brasileiro de pesquisa sobre a teoria da Justiça de Amartya Sen. Membro da Associação Brasileira de Ensino de Direito ABEDi. Membro do Grupo de Pesquisa em Direito Empresarial e Sustentabilidade, do Instituto Blumenauense de Ensino Superior. Passo Fundo. RS. Brasil. Currículo Lattes: http://lattes.cnpq.br/1318707397090296 - E-mail: sergiorfaquino@gmail.com

2 Acadêmico do quarto semestre do Curso de Direito da Faculdade Meridional - IMED. Membro do Grupo de Pesquisa "Ética, Cidadania e Sustentabilidade".

3 Acadêmica do terceiro semestre do Curso de Direito da Faculdade Meridional - IMED. Membro do Grupo de Pesquisa "Ética, Cidadania e Sustentabilidade".
} 
FERNANDES DE AQUINO, Sérgio Ricardo; DOS SANTOS, Wagner; FICAGNA, Victoria. Ética, moral e amizade em tempos líquidos: fundamentos críticos para uma práxis de direitos humanos. Revista Eletrônica Direito e Política, Programa de Pós-Graduação Stricto Sensu em Ciência Jurídica da UNIVALI, Itajaí, v.14, n.1, $1^{\circ}$ quadrimestre de 2019. Disponível em: www.univali.br/direitoepolitica - ISSN 1980-7791

proximidade entre as pessoas a fim de tornar eficaz o discurso dos Direitos Humanos.

PALAVRAS-ChAVE: Ética. Moral. Amizade. Direito Fraterno. Tempos Líquidos. Direitos Humanos.

\section{ABSTRACT}

The characterization of our time as "liquid time" shows the extent of human communication and the emptiness of the human relationships. Values such as Ethics, Moral, Friendship and Fraternity are considered disposable because nothing today is built to last or no one wants to mortgage the future. The purpose of this paper is to analyze whether Ethics, Moral, Friendship and Fraternity are still essential for the establishment of human relations in these liquid times. The method was the deductive. As part of the conclusions, it's possible to see that human relations cannot be developed in the empty axiological premises of liquid times, but need also this proximity between people to make Human Rights a way of global life.

KEYWORDS: Ethics. Moral. Friendship. Fraternal Right. Liquid Times. Human Rights.

\section{INTRODUÇÃO}

Antes de se iniciar o estudo proposto e explicar os seus fundamentos metodológicos, é necessário destacar uma categoria essencial para que se estabeleça com o leitor ou leitora um acordo semântico ${ }^{4}$ mínimo no intuito do raciocínio se desenvolver sem maiores dúvidas ou que se permita utilizar outros conceitos para estabelecerem a sua compreensão acerca daquilo que se expõe. A categoria indicada denomina-se Crítica.

Quando se utiliza o termo "fundamentos críticos", para fins de elaboração desta pesquisa bibliográfica, deve-se ter como pressuposto o pensamento de Kant na sua obra, Crítica da Razão Pura. No prefácio da segunda edição dessa obra - a qual encontra-se inclusa na referência da fonte estudada - o mencionado filósofo descreve que existe uma função negativa e uma positiva quanto ao uso da

\footnotetext{
4 "[...] ato pelo qual os envolvidos num processo comunicativo partilham os significados para as palavras e expressões que estão escrevendo ou falando". PASOLD, Cesar Luiz. Metodologia da pesquisa jurídica: teoria e prática. 13. ed. Florianópolis: Conceito Editorial, 2015, p. 204.
} 
FERNANDES DE AQUINO, Sérgio Ricardo; DOS SANTOS, Wagner; FICAGNA, Victoria. Ética, moral e amizade em tempos líquidos: fundamentos críticos para uma práxis de direitos humanos. Revista Eletrônica Direito e Política, Programa de Pós-Graduação Stricto Sensu em Ciência Jurídica da UNIVALI, Itajaí, v.14, n.1, $1^{\circ}$ quadrimestre de 2019. Disponível em: www.univali.br/direitoepolitica - ISSN 1980-7791

categoria Crítica. Quanto à dimensão negativa, trata-se de restringir a Razão, de propor os seus limites para não ampliar, indefinidamente, as características e o "ser" da experiência sensível para além daquilo que é.

No entanto, se essa restrição favorece a eliminação de algum obstáculo no qual impeça o uso legítimo da Razão para que não haja qualquer espécie de contradição, principalmente quanto ao seu uso prático, tem-se, nesse momento, um aspecto positivo ${ }^{5}$. A Razão, dentro dos limites propostos quanto ao seu exercício (função negativa), esclarecerá, sem deturpar o "ser" das experiências sensíveis como fenômenos ${ }^{6}$, qual é o seu entendimento (função positiva). Por esse motivo, a categoria Crítica não pode ser utilizada sem que haja uma preocupação quanto à conjugação das suas dimensões negativa e positiva.

\footnotetext{
5 "[...] Pode-se ter a impressão, num exame apresado deste trabalho, de que a sua utilidade [da Crítica] seja apenas negativa, a saber, de não nos arriscarmos jamais, com a razão especulativa, para além dos limites da experiência; e tal é, de fato, a sua primeira utilidade. Esta logo se torna positiva, porém, quando se percebe que os princípios com que a razão especulativa se arrisca para além de seus limites têm por resultado inevitável não de fato a ampliação, mas, sim, se os observa mais de perto, a contração do uso de nossa razão, já que eles ameaçam alargar indefinidamente os limites da sensibilidade, aos quais eles próprios pertencem, e assim anular o uso puro (prático) da razão. Assim, uma Crítica que limita aquele primeiro uso é realmente negativa, mas, na medida em que suprime ao mesmo tempo um obstáculo que limita o segundo uso, ou mesmo que ameaça destruí-lo, ela tem uma utilidade positiva e muito importante, reconhecível tão logo se esteja convencido de que há um uso prático absolutamente necessário da razão pura (o moral), no qual ela se estende inevitavelmente além dos limites da sensibilidade sem necessitar de qualquer assistência da especulativa, mas assegurada contra o efeito contrário desta para não cair em contradição consigo mesma". KANT, Immanuel. Crítica da razão pura. Tradução de Fernando Costa Mattos. Bragança Paulista, (SP); Petrópolis, (RJ): Editora Universitária São Francisco/Vozes, 2012, par. B XXIV/BXXV).
}

6 "[...] "na medida em que podem ser pensados como objetos segundo a unidade de categorias, os fenômenos se denominam Phaenomena. Se suponho coisas que são meros objetos do entendimento e, não obstante, podem ser dadas a uma intuição, ainda que não sensível (portanto coram intuitu intellectuali) - então tais coisas se denominariam Noumena (intelligiblia). Poder-seia pensar, então, que o conceito de fenômeno, tal como limitado pela estética transcendental, já forneceria por si mesmo a realidade objetiva dos noumenorum e justificaria a divisão dos objetos em phaenomena e noumena, portanto também do mundo em um mundo dos sentidos e outro do entendimento (mundus sensibilis et intelligiblis), e isso de tal modo que a diferença não dissesse respeito apenas à forma lógica do conhecimento claro ou obscuro de uma única e mesma coisa, mas à diferença no modo como os objetos podem ser originariamente dados ao nosso conhecimento - diferença na qual eles se distinguem uns dos outros em si mesmos segundo a espécie. Pois, se os sentidos nos representam algo somente tal como ele aparece, este algo também tem de ser, em si mesmo, uma coisa e um objeto de uma intuição não sensível , i. e., do entendimento; ou seja, tem de ser possível um conhecimento em que não se encontre nenhuma sensibilidade e que tenha apenas realidade objetiva absoluta, um conhecimento, com efeito, pelo qual objetos nos seja representados tal como são, ao passo que no uso empírico de nosso entendimento as coisas só são conhecidas tal como aparecem. KANT, Immanuel. Crítica da razão pura. par. A 249. Grifos originais da obra estudada. 
FERNANDES DE AQUINO, Sérgio Ricardo; DOS SANTOS, Wagner; FICAGNA, Victoria. Ética, moral e amizade em tempos líquidos: fundamentos críticos para uma práxis de direitos humanos. Revista Eletrônica Direito e Política, Programa de Pós-Graduação Stricto Sensu em Ciência Jurídica da UNIVALI, Itajaí, v.14, n.1, $1^{\circ}$ quadrimestre de 2019. Disponível em: www.univali.br/direitoepolitica - ISSN 1980-7791

A partir dessa condição - e ao se vislumbrar o atual cenário mundial, principalmente sob o ângulo da socialidade com o Outro -, percebe-se o constante afastamento das pessoas, dos cidadãos para com seu semelhante, tornando-o um espaço menos democrático. As adversidades, a facilidade tecnológica das comunicações, a velocidade com que se recebe as informações, o medo do desconhecido e do novo, são fatores que caracterizam esse tempo líquido, no qual tudo é momentâneo, efêmero, transitório.

A disseminação da internet, a necessidade do consumismo desregrado, a capacidade de poder selecionar no seu ambiente quem irá frequenta-lo - deixando o ser humano em uma zona de conforto - mostram o abandono de sensações de liberdade (responsável), de prazer, de felicidade e compartilhamento por estar com o Outro. O Homem acredita apenas no "Eu" e abandona o "Outro".

O presente texto busca, segundo a perspectiva de Zygmunt Bauman, demonstrar como o ser humano se torna menos sociável, almejando a solidão e a preguiça de buscar novas aventuras e o desconhecido, no qual, em momentos de futilidade e cobiça por bens materiais ou a caminhada para outra posição social, deixa de perceber o Outro, de ter atitudes responsáveis, de criar laços de proximidade. A sociedade, hoje, mergulha, mais e mais, na dimensão oceânica desse tempo líquido sem perceber, ao mesmo tempo, o esvaziamento de significados históricos propostos pelos Direitos Humanos.

Essas ações afetam a todos, individualizam - de modo irresponsável - o ser humano, afasta-o dos outros seres humanos e despreza-se valores como a Amizade e Fraternidade. É a partir da Amizade que a Moral favorece atitudes éticas fundamentais para o fortalecimento de um cenário social mais equilibrado e harmônico no mundo.

O problema de pesquisa posto para este estudo pode ser expresso na seguinte indagação: Ética, Moral, Amizade são vetores axiológicos descartáveis para a constituição das relações humanas e a viabilidade dos Direitos Humanos neste tempo líquido? A resposta para essa pergunta - a formulação de nossa provisória hipótese de pesquisa - é inicialmente negativa, pois todos os valores descritos 
FERNANDES DE AQUINO, Sérgio Ricardo; DOS SANTOS, Wagner; FICAGNA, Victoria. Ética, moral e amizade em tempos líquidos: fundamentos críticos para uma práxis de direitos humanos. Revista Eletrônica Direito e Política, Programa de Pós-Graduação Stricto Sensu em Ciência Jurídica da UNIVALI, Itajaí, v.14, n.1, $1^{\circ}$ quadrimestre de 2019. Disponível em: www.univali.br/direitoepolitica - ISSN 1980-7791

revelam a necessidade da identificação de seus conteúdos no decorrer do tempo a fim de tornar possível não apenas a aplicação dos Direitos Humanos, mas de que modo esse se constitui a partir das características culturais de cada região do planeta.

Por esse motivo, o objetivo geral desta pesquisa é analisar se Ética, Moral, Amizade são, ainda, vetores que favorecem a disseminação dos Direitos Humanos nesse tempo líquido. Os objetivos específicos utilizados para viabilizar a finalidade principal são: a) definir o que é a Ética e Moral no tempo líquido; b) avaliar a importância da Amizade e Fraternidade como pressupostos de viabilidade Moral e Direitos Humanos às relações humanas; c) identificar como essas categorias se tornam o fundamento crítico para se compreender o projeto de civilização desenhado pelos Direitos Humanos.

Busca-se demonstrar ao longo do texto a importância do convívio, do acolher o Outro a partir de suas diferenças, de como o diálogo com as adversidades alimenta a moral humana. Ao se compreender o ser que se manifesta diante do "Eu", presencia-se a construção da Amizade, fundamental para a convivência em harmonia e humanizar mais o Homem. Eis o desafio caótico da Moral e da compreensão histórica dos Direitos Humanos.

O método de investigação utilizado foi 0 Dedutivo ${ }^{7}$, cuja premissa maior é a existência de valores como Ética, Moral, Amizade e Fraternidade e o como esses vetores axiológicos são compreendidos ou utilizado no tempo líquido - premissa menor. As técnicas de pesquisa acionadas foram a Pesquisa Bibliográfica e Documental, Categorias ${ }^{8}$, Conceitos Operacionais ${ }^{9}$,

\footnotetext{
7 "[...] base lógica da dinâmica da Pesquisa Científica que consiste em estabelecer uma formulação geral e, em seguida, buscar as partes do fenômeno de modo a sustentar a formulação geral". PASOLD, Cesar Luiz. Metodologia da pesquisa jurídica: teoria e prática. p. 213.

8 "[...] palavra ou expressão estratégica à elaboração e/ou à expressão de uma ideia". PASOLD, Cesar Luiz. Metodologia da pesquisa jurídica: teoria e prática. p. 205.

9 "[...] definição estabelecida ou proposta para uma palavra ou expressão, com o propósito de que tal definição seja aceita para os efeitos da ideia exposta". PASOLD, Cesar Luiz. Metodologia da pesquisa jurídica: teoria e prática. p. 205.
} 
FERNANDES DE AQUINO, Sérgio Ricardo; DOS SANTOS, Wagner; FICAGNA, Victoria. Ética, moral e amizade em tempos líquidos: fundamentos críticos para uma práxis de direitos humanos. Revista Eletrônica Direito e Política, Programa de Pós-Graduação Stricto Sensu em Ciência Jurídica da UNIVALI, Itajaí, v.14, n.1, $1^{\circ}$ quadrimestre de 2019. Disponível em: www.univali.br/direitoepolitica - ISSN 1980-7791

Os valores Ética, Moral, Amizade e Fraternidade são indícios necessários não apenas à convivência humanas, mas, também, vetores de construção para um outro Direito: o Direito Fraterno, no qual compreenda a sociedade em que vive, utilizando e disseminando ideais de justiça, equidade e igualdade para com os cidadãos, pois a Ética, fundada pela Moral, orienta o agir ao bem comum e a Amizade favorece a presença coerente ${ }^{10}$ de uma fala sensata comum - própria dos Direitos Humanos - a fim de se estabelecer critérios de respeito e responsabilidades mútuas no intuito de se impulsionar a viabilidade das "utopias concretas $^{11 "}$ civilizacionais próprias do século XXI, as quais não se exaurem pela sua dimensão líquida.

\section{1 ÉTICA E MORAL NO TEMPO LÍQUIDO}

O ser humano, como já é bem conhecido, é um ser social, cujo necessita estar presente do Outro, dividindo suas conquistas, afinidades, conhecimentos e até mesmo suas desavenças. No entanto, esse relacionamento, constantemente presenciado - muito mais frequente e facilitado nos tempos atuais com a internet - em nosso cotidiano deve pautar-se em princípios os quais regulem esta

10 "[...] creio que coerência é, enfim, o termo correto e que lança ponte [...]: o que descubro no pensamento de alhures ou daqui é sempre 'co-erente', uma vez que resistindo efetivamente em conjuntos e justificando-se. Assim, com efeito, a inteligência é esse recurso comum, sempre em desenvolvimento, bem como indefinidamente partilhável, de apreender coerências e comunicar-se através delas. Heráclito já dizia: 'Comum a todos é o pensar', phronein. O que estabeleceu como princípio que não existe nada, de qualquer cultura que seja, que não seja em princípio inteligível é este efetivamente, mais uma vez, o único transcendental que reconheço: não em função das categorias dadas, em nome de uma razão pré-formada, mas como exigência que forma horizonte e jamais se detém (e corespondendo, a esse título, ao universal). Isso, portanto, sem resíduo. De maneira absoluta. Ainda que os esforços dos antropólogos nunca sejam plenamente recompensados; ainda mesmo que eu mesmo nunca tenha certeza de ter conseguido ler o suficiente...". JULLIEN, François. O diálogo entre as culturas: do universalismo ao multiculturalismo. Tradução de André Telles. Rio de Janeiro: Zahar, 2009, p. 175/176.

11 "[...] O ponto de contato entre sonho e vida, sem o qual o sonho produz apenas utopia abstrata e a vida, por seu turno, apenas trivialidade, apresenta-se na capacidade utópica colocada sobre os próprios pés, a qual está associada ao possível-real. [...] aqui teria lugar o conceito de utópicoconcreto, apenas aparentemente paradoxal, ou seja, um antecipatório que não se confunde com o sonhar utópico abstrato, [...]". BLOCH, Ernst. O princípio esperança. Tradução de Nélio Schneider. Rio de Janeiro: EdUERJ/Contraponto, 2005, v.1, p. 145. 
FERNANDES DE AQUINO, Sérgio Ricardo; DOS SANTOS, Wagner; FICAGNA, Victoria. Ética, moral e amizade em tempos líquidos: fundamentos críticos para uma práxis de direitos humanos. Revista Eletrônica Direito e Política, Programa de Pós-Graduação Stricto Sensu em Ciência Jurídica da UNIVALI, Itajaí, v.14, n.1, $1^{\circ}$ quadrimestre de 2019. Disponível em: www.univali.br/direitoepolitica - ISSN 1980-7791

interação. Ambiguidade, ambivalência, incertezas: exigências de tempos líquidos ${ }^{12}$.

Utilizar da Moral e da Ética é essencial para a construção de um ambiente mais sadio e propicio a construção de um sociedade mais acolhedora e cidadã. Mais ainda, aproveitar-se destes princípios acaba por deixar o Homem mais perto do Outro, por consequência, o Direito - sendo expressão dos conflitos entre os seres humanos - usufrui deste ambiente, sendo mais fraterno e acolhedor. É uma tarefa árdua falar de Ética e Moral em esferas separadas, ainda mais de uma Ética sem Moral, pois ambas precisam se compreender, se complementarem.

A Moral é caracterizada por um sentimento, num primeiro momento, mais íntimo de cada ser humano, por abranger aos valores intrínsecos do Homem ${ }^{13}$. Desde nascituro, o homem já nasce com valores e direitos - como liberdade e dignidade ${ }^{14}$ - com o passar do tempo, acaba por reconhece-los, e adquire novos valores a partir de seus aprendizados e vivencias. Nesse caso, a Moral de cada um encontra-

12 "[...] os líquidos, diferentemente dos sólidos, não mantêm sua forma com facilidade. Os fluídos, por assim dizer, não fixam o espaço nem prendem o tempo. Enquanto os sólidos têm dimensões espaciais claras, mas neutralizam o impacto e, portanto, diminuem a significação do tempo (resistem efetivamente a seu fluxo ou o tornam irrelevante), os fluídos não se atêm muito a qualquer forma e estão constantemente prontos (e propensos) a mudá-la; assim, para eles, o que conta é o tempo, mais do que o espaço que Ihes toca ocupar; espaço que, afinal, preenchem apenas por um momento. Em certo sentido, os sólidos suprimem o tempo; para os líquidos, ao contrário, o tempo é o que importa". BAUMAN, Zygmunt. Modernidade líquida. Tradução de Plínio Dentzien. Rio de Janeiro: Zahar, 2001, p. 8.

13"Eticamente, a moralidade é antes do ser. Mas ontologicamente não há nada antes do ser, como ontologicamente também o "antes do ser" é outro ser. A moralidade é antes do ser somente em seu próprio sentido moral de "antes"; isto é, no sentido de ser "Melhor" - Mas no sentido ontológico, o sentido que predomina sempre que os dois sentidos competem no campo do ser, o campo em que todos estamos, o ser é antes da moralidade; o eu moral não pode ser senão um eu moral. Ontologicamente, a moralidade só pode vir depois do ser, isto é, ou como determinado resultado do ser, ou como uma regra obrigada a admitir prioridade do ser por querer justificar-se a si mesma em termos de ser." BAUMAN, Zygmunt. Ética pós-moderna. Tradução: João Rezende Costa, São Paulo: Paulus, 1997, p. 89.

14 "O homem que quer ser digno deve dirigir a si mesmo de forma a garantir sua dignidade. Se deixa na mão do Estado torna-se uma coisa, um escravo de forças externas. Agora se luta por sua dignidade é verdadeiramente um ser humano, alguém em busca de sua unidade, de ser uma pessoa completa e garantindo no mundo prático aquela dignidade que em potencial é de natureza". SOARES, Josemar Sidinei; CHIARA LOCCHI, Maria. O papel do indivíduo na construção da dignidade da pessoa humana/ The individual role in the construction of the human person dignity. Revista Brasileira de Direito, Passo Fundo, v. 12, n. 1, p. 36, jun. 2016. ISSN 2238-0604. Disponível em: <https://seer.imed.edu.br/index.php/revistadedireito/article/view/1118/835>. Acesso em: 20 ago. 2017. 
FERNANDES DE AQUINO, Sérgio Ricardo; DOS SANTOS, Wagner; FICAGNA, Victoria. Ética, moral e amizade em tempos líquidos: fundamentos críticos para uma práxis de direitos humanos. Revista Eletrônica Direito e Política, Programa de Pós-Graduação Stricto Sensu em Ciência Jurídica da UNIVALI, Itajaí, v.14, n.1, $1^{\circ}$ quadrimestre de 2019. Disponível em: www.univali.br/direitoepolitica - ISSN 1980-7791

se em constante mutação, em um estado de frenesi perante as novas vivencias, perante a descoberta do novo, do diferente de si. A Moral é esse fenômeno caótico $^{15}$, na qual não pode ser contida, determinada pelas exatas fronteiras da lógica.

O agir moral se expressa como uma fração da liberdade e da dignidade de cada um. A mencionada atitude propicia a liberdade para usufruir do novo, para demonstrar e colocar em um debate os valores pessoais, bem como garante desbravar o mundo das diferenças. Ao se compreender a liberdade, outra epifania aparece: a dignidade ${ }^{16}$ de cada ser humano. Essa condição traz consigo o respeito, o zelo à integridade e, apoiados pela Moral, possibilita a convivência com o Outro. Vislumbra-se, nesse horizonte, a importância da dignidade, a qual se manifesta pela presença do Outro. Aqui ocorre o Bem Moral ${ }^{17}$.

A aproximação entre as pessoas, conforme as diretrizes da Moral, beneficia um diálogo harmônico e respeitoso, cria um ambiente Ético de responsabilidades além de sua condição puramente normativa. Na Ética, nem sempre se visualiza uma soma de valores, de diferenças para se desbravar o desconhecido e se deparar com o imperfeito. Sem a presença da Moral, o significado teleológico da Ética perde seu substrato e se inicia tão somente o império do (indiferente) dever-ser ${ }^{18}$.

\footnotetext{
15 "[...] Ser caótico é estar desprovido de estrutura - se 'estrutura' significar uma distribuição assimétrica de probabilidades, uma não aleatoriedade dos eventos. [...] O caos é o que há de mais aterrador para as promessas acenadas pela rotina do estabelecido. A sociedade é uma fuga do medo, mas também é o solo fértil desse medo, e dele se alimenta, é dele a garra com que ela nos detém e extrai a sua força". BAUMAN, Zygmunt. A vida em fragmentos: sobre a ética pósmoderna. Tradução de Alexandre Werneck. Rio de Janeiro: Jorge Zahar, 2011, p. 25-27.
}

16 "Só há dignidade, portanto, quando a própria condição humana é entendida, compreendida e respeitada, em suas diversas dimensões, o que impõe, necessariamente, a expansão da consciência ética como pratica diuturna de respeito à pessoa humana". BITTAR, Eduardo C. B. O direito na pós-modernidade: e reflexões frankfurtianas. 2. ed. Rio de Janeiro: Forense Universitária, 2009, p. 302.

17 "Claro que há a beleza, mas ela é boa para a visão; claro que há a ciência, mas ela é boa para resolver problemas; claro que existe um temperamento afável, mas a afabilidade é boa para a convivência sem problemas. A bondade desses bens - estéticos, técnicos, psicológicos - é relativa a determinados interesses, aspirações e necessidades. A bondade 'em si' - sem 'para' - só convém a uma vontade boa, a uma pessoa boa. $O$ bem irrestrito, sem relações nem paliativos, é o bem moral". CORTINA, Adela. Ética sem moral. Tradução de Marcos Marcionilo. São Paulo: Martins Fontes, 2010, p. 190.

18 "[...] Quando instado a explicar, no julgamento de Nuremberg, por que não renunciou ao comando Einsatzgruppe cujas ações pessoalmente desaprovava, Ohlendorf invocou precisamente este senso 
FERNANDES DE AQUINO, Sérgio Ricardo; DOS SANTOS, Wagner; FICAGNA, Victoria. Ética, moral e amizade em tempos líquidos: fundamentos críticos para uma práxis de direitos humanos. Revista Eletrônica Direito e Política, Programa de Pós-Graduação Stricto Sensu em Ciência Jurídica da UNIVALI, Itajaí, v.14, n.1, $1^{\circ}$ quadrimestre de 2019. Disponível em: www.univali.br/direitoepolitica - ISSN 1980-7791

Quando esse encontro de diferenças ocorre, percebe-se um sentimento de Alteridade com o Outro ${ }^{19}$, pois ali visualiza-se uma parte do "Eu" no "Outro", aceitando-o também como um cidadão e aprendendo com as diferenças ali encontradas, tendo responsabilidade ${ }^{20}$ social e Ética com aquele ali presente. Também é necessário um grau de tolerância percebida entre os indivíduos, pois a tolerância ${ }^{21}$ pressupõe um caráter de compreensão do outro - seus anseios, medos, valores, adversidades, e até de sua dignidade - e esta compreensão acaba por aproximar os seres, o "eu" acolhe 22 o Outro.

de responsabilidade: se expusesse as ações de sua unidade para se ver livre de obrigações que, garantiu, o indignavam, estaria deixando que seus homens fossem 'erroneamente acusados'. Obviamente, Ohlendorf esperava que a mesma responsabilidade paternalística em relação a 'seus homens' seria praticada por seus superiores para com ele; isso o eximia da preocupação com a avaliação moral de suas ações, que poderia com segurança deixar a cargo dos que o comandavam". BAUMAN, Zygmunt. Modernidade e holocausto. Tradução de Marcus Penchel. Rio de Janeiro: Zahar, 1998, p. 42.

19 "O ser humano percebe o outro como um eu simultaneamente diferente e igual a ele. O Outro partilha assim uma identidade comigo embora conservando a sua diferença. Quando aparece como semelhante, carrega um potencial de fraternidade." MORIN, Edgar. 0 método 6: Ética. Tradução de Juremir Machado da Silva. 3.ed. Porto Alegre: Sulina, 2007, p. 103.

20 "A responsabilidade, na medida em que permanece apenas moral, na medida em que nenhuma tentativa se fez para exauri-la numa lista de obrigações e direitos concedidos, não tem significado nesse sentido. A face, com que a responsabilidade se confronta, levanta exigências por sua insignificância, pela irrealização de seu potencial de assumir e portar significados. Será somente mais tarde, quando eu reconhecer a presença da face como minha responsabilidade, que nós dois, eu e o próximo, adquirimos significados: Eu sou eu, quem sou responsável, ele é ele, a quem eu atribuo o direito de fazer-me responsável. E nessa criação de significado do Outro, e assim também de mim mesmo, que chega a mim minha liberdade, minha liberdade ética". BAUMAN, Zygmunt. Ética pós-moderna. p. 102. Grifos originais da obra estudada.

21 "A Tolerância torna visíveis os limites de nossas certezas e acolhe essa diferença que está além das fronteiras perceptivas do 'Eu'. Essa postura é inexistente por aquele que pratica o seu contrário - a intolerância27 -, porque a ausência desse terreno fértil, de se acolher a diferença humana alheia, impõe um modus vivendi sem liberdades, sem proximidade. É a negação da condição (e natureza) humana. Tolerar exige, sob esse argumento, o Perdão, pois, como salienta Voltaire, é o fundamento que se manifesta a partir do reconhecimento no qual se comunga nossas fragilidades, nossos erros. Ao se admitir essa condição, intrasubjetiva e intersubjetiva, resta a indagação: Por que não perdoar? Percebe-se nessa ação uma aposta de regeneração, ao contrário da intolerância, que dissemina atitudes destrutivas. O improvável se corporifica e resiste, manifesta-se contra a violência, a crueldade, as imposições culturais arbitrárias e regenera as relações humanas tornando-as mais amistosas e sadias. Esse é o vínculo de Responsabilidade na qual se constitui historicamente por meio do 'estar junto', e se torna o sedimento que amplia o exercício habitual da Tolerância". ZAMBAM, Neuro José; AQUINO, Sérgio Ricardo Fernandes de. Tolerância: reflexões filosóficas, políticas e jurídicas para o século XXI. Revista da AJURIS. Porto Alegre, v. 142, n. 137, março de 2015, p. 374. Disponível em: http://www.ajuris.org.br/OJS2/index.php/REVAJURIS/article/view/389/323. Acesso em 19 de jul. de 2016.

22 "Talvez, fosse interessante rever os caminhos da tolerância como espaço do afeto, do amor, da dignidade por um movimento singular: o acolhimento. [...] $\mathrm{O}$ incerto, o desconhecido, o impreciso dialoga com a perfeição, a certeza, a objetividade. Tolerar significa acolher o Outro como igual a 
FERNANDES DE AQUINO, Sérgio Ricardo; DOS SANTOS, Wagner; FICAGNA, Victoria. Ética, moral e amizade em tempos líquidos: fundamentos críticos para uma práxis de direitos humanos. Revista Eletrônica Direito e Política, Programa de Pós-Graduação Stricto Sensu em Ciência Jurídica da UNIVALI, Itajaí, v.14, n.1, $1^{\circ}$ quadrimestre de 2019. Disponível em: www.univali.br/direitoepolitica - ISSN 1980-7791

Essa aproximação, esse acolhimento com o outro, constrói experiências e conhecimentos partilhados entre a sociedade e principalmente entre os indivíduos ali postos. Essas emoções compartilhadas, causam um espanto no viver diário de cada um, fomentando um viver mais harmônico. Nesse caso, há uma dinâmica social de compartilhamento de emoções, moldando e transformando a moral de cada um, tornando cada vez mais o homem mais sociável e propicio a uma boa moral. Ocorre a minimização do individualismo - tão presente nos dias atuais - e a maximização do ser, do "eu plural, multicultural"23" habitualmente praticada. Todas essas situações ampliam, mais e mais, a linguagem dos Direitos Humanos fora de uma perspectiva exclusivamente normativa.

Quando a proximidade é habitualmente vivenciada, essa causa maior inclusão entre os seres humanos, sendo cada vez mais ligada e intima. Essa condição permitirá a construção de um relacionamento afetivo de Amizade ${ }^{24}$. A relação fundada numa postura amistosa compreende a valoração do vínculo responsável criado e, por conseguinte, haverá maior respeito e humanização com o Outro. As pessoas tornam-se mais sensíveis, reconhecem virtudes e vícios comuns, aprendem a conviver nessa relação de estar-junto com o Outro no mundo.

mim. [...] A Tolerância percebida como movimento acolhedor é pressuposto ético de cada grupo, respeitando suas características". AQUINO, Sergio Ricardo Fernandes de. O Direito em busca de sua humanidade: diálogos errantes. Curitiba: CRV, 2014b, p. 33/34.

23 "[...] a luta multicultural está enraizada no processo histórico de formação dos países americanos, que passaram por um processo de conquista e colonização, seguido de uma política de assimilação forçada e de eliminação da identidade dos povos que habitavam as terras "descobertas". Nesse sentido, o acelerado processo de globalização que atravessa o mundo, gera novos marcos de regulação e novos cenários que conectam realidades e culturas há muito pouco tempo distantes, mas que acentuam as diferenças sociais e as tensões étnicas, que fez emergir o multiculturalismo, a interculturalidade e a preocupação com as questões identitárias e culturais. A questão multicultural está presente na maioria dos países formados por uma população heterogênea, por instituições democráticas e atingidos pelas consequências desastrosas dos processos de globalização hegemônica. Esses países apresentam minorias5 fortemente discriminadas e exploradas, que carregam o peso da colonização, da tentativa de assimilação forçada, de incorporação ao cenário nacional e da superioridade de uma cultura dominante, que considera todos os homens como "livres e iguais". SPAREMBERGER, Raquel Fabiana; GABRIEL, José Elias. Multiculturalismo de negação: um olhar para a realidade da prisão da mulher estrangeira/Multiculturalismo of negativo: a look at the reality of foreign's women prison. Revista Videre, Dourados, v. 9, n. 17, p. 141, jan./jul. 2017. ISSN 2177-7837. Disponível em: <http:// http://ojs.ufgd.edu.br/index.php/videre/article/view/6113>. Acesso em: 20 ago. 2017.

24 "[...] a verdadeira Amizade estabelece um vínculo ético de fraternidade quase sagrado entre amigos. [...] A qualidade da pessoa importa mais do que a quantidade das suas ideias ou opiniões". MORIN, Edgar. O método 6: Ética. p. 107. 
FERNANDES DE AQUINO, Sérgio Ricardo; DOS SANTOS, Wagner; FICAGNA, Victoria. Ética, moral e amizade em tempos líquidos: fundamentos críticos para uma práxis de direitos humanos. Revista Eletrônica Direito e Política, Programa de Pós-Graduação Stricto Sensu em Ciência Jurídica da UNIVALI, Itajaí, v.14, n.1, $1^{\circ}$ quadrimestre de 2019. Disponível em: www.univali.br/direitoepolitica - ISSN 1980-7791

Contraposto a esses ideais, percebe-se a intensa fragilidade das relações entre todos os povos. Tem-se, hoje, uma sociedade incapaz de reconhecer seus valores com receio do que há de diferente, ou melhor, com medo de buscar novos conhecimentos e aventuras existenciais. Os indivíduos estão acorrentados na sua acomodação e a proteção de uma tela de computador ou smartphone, selecionando como, quando e com quem querem socializar, retirando de si o fardo da responsabilidade social, consigo e com o Outro.

Ao mesmo tempo em que se observa todas as culturas e sociedades - o mundo em si - aberto a todos pela comunicação ${ }^{25}$, encontra-se, também, seres humanos fechados à vida. Presencia-se uma fragilidade nas relações entre os cidadãos. Não há mais o amor e o afeto, ou a experiência da felicidade ou tristeza de um momento com o Outro. O que nos resta hoje é um tempo de aparências, ou seja, busca-se mascarar a dor e sofrimento, a falta de amor e carinho do "Eu" com o "Outro". As relações estão fluindo pelos dedos de cada ser, deixando-as morrerem com a falta de cuidado e afeto.

Como contraditório, o ser deve novamente voltar a convivência utilizando-se da Moral como fundamento do agir ético. Deve-se fortalecer os vínculos e se criar Amizades duradouras e saudáveis. A Ética não aparece aqui como princípio normativo capaz de salvar todos os seres dessa aberração causada pela ausência de socialidade, mas precisa resgatar novamente a necessidade de o Homem relacionar-se com o Outro, já que essa é a condição primária para a viabilidade dos Direitos Humanos.

É essencial aos seres humanos atuar na esfera social pautado em sua Moral ademais de sua boa-moral - facilitando o convite ao diálogo e novas experiências e conhecimento. Todos esses fatores acarretam na formulação de uma Ética ${ }^{26}$ mais

\footnotetext{
25 "Tal como antes, o termo se refere a uma sociedade que admite francamente sua própria incompletude, e portanto é ansiosa em atender suas próprias possibilidades ainda não-intuídas, muito menos exploradas. Mas significa, além disso, uma sociedade impotente, como nunca antes, em decidir o próprio curso com algum grau de certeza e em proteger o itinerário escolhido, uma vez selecionado". BAUMAN, Zygmunt. Tempos líquidos. Tradução de Carlos Alberto Medeiros, Rio de Janeiro: Jorge Zahar, 2007, p. 13.

26 "Um dos resultados a serem usufruídos é o fortalecimento da democracia como uma forte vinculação ao agir ético, por se tratar de uma razoável consciência com respeito aos direitos
} 
FERNANDES DE AQUINO, Sérgio Ricardo; DOS SANTOS, Wagner; FICAGNA, Victoria. Ética, moral e amizade em tempos líquidos: fundamentos críticos para uma práxis de direitos humanos. Revista Eletrônica Direito e Política, Programa de Pós-Graduação Stricto Sensu em Ciência Jurídica da UNIVALI, Itajaí, v.14, n.1, $1^{\circ}$ quadrimestre de 2019. Disponível em: www.univali.br/direitoepolitica - ISSN 1980-7791

viva e presente nas relações diárias, cujos significados construam um cenário de tolerância, respeito e cidadania com todos a sua volta. Contribuir com um ambiente ético é nada mais do que também auxiliar na formulação de um Direito Fraterno, a partir de pressupostos da Moral e da Amizade. Eis uma práxis ${ }^{27}$ desafiadora de Direitos Humanos.

\section{2 ÉTICA, MORAL E AMIZADE: A PRÁXIS DOS DIREITOS HUMANOS}

No cenário de tempos líquidos, o qual se vivencia, preconizado por Bauman, se instaura na sociedade cotidianamente de forma vertiginosa uma complexidade de interações sociais, de princípios que regem os vínculos entre os seres humanos, todavia, de certa forma, estes, não caracterizam sua essência primordial de alteridade, Amizade e fraternidade, se esvaindo ao mesmo tempo em que se firma uma nova era, insuficiente de valores.

O sentido normativo da Ética se dilui sob a necessidade de resgate da Moral nesses tempos líquidos. É a partir dessa condição de socialidade da Moral na qual a Amizade se torna vetor de integração entre as pessoas e tornam o cotidiano um espaço democrático para se identificar as atitudes e pensamentos nos quais favorecem essa mútua responsabilidade, não obstante hajam diferentes adversidades conforme cada contexto de proximidade entre os seres humanos e o seu cotidiano ${ }^{28}$.

próprios dos humanos. A ética possibilita que sejam incluídos os excluídos, como instituintes do modelo democrático". PIRES, Cecília. Leituras filosóficas passadas a limpo: temas e argumentos. Passo Fundo, (RS): IFIBE, 2016, p. 32.

27 "[...] Na práxis social, todavia, quando o sujeito da violência visa a grupos sociais, estes não se deixam objetivas integralmente, assumem-se como sujeitos e resistem à violência. Constroem uma antipraxis. Se, para o colonizador, o colonizado é objeto passível de violência, a antipraxis frente ao procedimento colonialista transforma-se, para ele, em práxis emancipatória". PIRES, Cecília. Leituras filosóficas passadas a limpo: temas e argumentos. p. 35.

28 "O direito é um fato social e, por isso mesmo, é um fato humano. A condição humana é, em primeiro plano, uma questão de vida material (de sobrevivência concreta e corporalmente) e o direito nasce como um regulador da convivência humana. Por conseguinte, os pressupostos do direito só têm razão de ser quando forem contextuais, quando tiverem como parâmetro a vida real material. Para ser contextualizada, a teoria deve assumir o compromisso com a construção de críticas emancipatórias do real. Em resumo, precisa se preocupar com a função social do conhecimento, devendo ser consciente do contexto no qual e para o qual aponta, sob pena de recair 
FERNANDES DE AQUINO, Sérgio Ricardo; DOS SANTOS, Wagner; FICAGNA, Victoria. Ética, moral e amizade em tempos líquidos: fundamentos críticos para uma práxis de direitos humanos. Revista Eletrônica Direito e Política, Programa de Pós-Graduação Stricto Sensu em Ciência Jurídica da UNIVALI, Itajaí, v.14, n.1, $1^{\circ}$ quadrimestre de 2019. Disponível em: www.univali.br/direitoepolitica - ISSN 1980-7791

Nessa concepção, ainda na antiguidade, entre os gregos, se discutia o conceito de Amizade, a relação desta, como princípio fomentador de vínculos de amabilidade e altruísmo entre as pessoas. Logo, os ensinamentos deixados por Aristóteles, se perpetuam até hoje, onde o significado desta palavra, muitas vezes deslembrado pelos indivíduos, se torna a fonte primordial para o reestabelecimento dos nexos interpessoais.

Segundo Aristóteles, a Amizade é uma virtude que cada um traz dentro de si, onde o intento desta condição, seria prosperar uma índole de generosidade, assim, as pessoas a medida que, colocado em prática este tributo, tornar-se-ão dignas de boas ações, assim sendo, boas pessoas, suscitando a disposição de fazer o bem, levando sempre em conta e como princípio fundamental, a questão da alteridade, pois, quando se enxerga o lado do outro e se compreende seu espaço, todos se tornam merecedores do estar-junto ${ }^{29}$ com alguém, com um amigo, e consequentemente, estabelecendo elos de uma cooperação mútua ${ }^{30}$.

A condição de humanidade que se instala e na qual estamos expostos, advindo de uma trajetória histórica conflituosa em diversos segmentos de convívio social, que,

em justificação ideológica do sistema hegemônico e abstrato dos direitos humanos. O conhecimento é um bem social que não pode ser posto à privatização, nem tampouco à valoração utilitarista". AQUINO, Sérgio Ricardo Fernandes de; GRUBBA, Leilane Serratine. Direitos Humanos: o problema do contexto/Human Rights: the problem of context. Revista Direito e Política, Itajaí, v. 10, n. 3, p. 1971, 2015. ISSN 1980-7791. Disponível em: <https://siaiap32.univali.br/seer/index.php/rdp/article/view/8027/4575>. Acesso em: 20 ago. 2017.

29 "[...] O estar-junto moral ou político, tal como prevaleceu na modernidade, não é senão uma forma profana de religião. Ou, ainda, ele exprime bem a história da salvação, de início cristã: espera da parusia, depois progressista: mito do desenvolvimento, particularmente forte no século XIX. Mas a partir do momento em que o fundamento divino perde sua substância, do momento em que o progresso não é mais considerado como um imperativo categórico, a existência social é, desde então, devolvida a si própria. Para ser mais preciso, a divindade não é mais uma entidade tipificada e unificada, mas tende a se dissolver no conjunto coletivo para se tornar o 'divino social'. É quando o mundo é devolvido a si mesmo, quando vale por si mesmo, que vai acentuar o que me liga ao outro: o que se pode chamar 'religação'". MAFFESOLI, Michel. No fundo das aparências. Tradução de Bertha Halpern Gurovitz. 3. ed. Petrópolis, (RJ): Vozes, 2005, p. 27.

30 "A Amizade perfeita é a dos homens que são bons e afins na virtude, pois esses desejam igualmente bem um ao outro enquanto bons, e são bons em si mesmos. Ora, os que desejam bem aos seus amigos por eles mesmos são os mais verdadeiramente amigos, porque o fazem em razão da sua própria natureza e não acidentalmente". ARISTÓTELES, Ética a Nicômacos. Tradução de Mário da Gama Kury. 4. ed. Brasília: Editora Universidade de Brasília, 2001, par. 1156b. 
FERNANDES DE AQUINO, Sérgio Ricardo; DOS SANTOS, Wagner; FICAGNA, Victoria. Ética, moral e amizade em tempos líquidos: fundamentos críticos para uma práxis de direitos humanos. Revista Eletrônica Direito e Política, Programa de Pós-Graduação Stricto Sensu em Ciência Jurídica da UNIVALI, Itajaí, v.14, n.1, $1^{\circ}$ quadrimestre de 2019. Disponível em: www.univali.br/direitoepolitica - ISSN 1980-7791

destarte, nos torna seres humanos falhos, fracos, instáveis, transitórios e inepto de princípios.

Parece fundamental que a questão da Alteridade e da Amizade são necessárias para que o Outro seja reconhecido na sua singularidade, na sua existência no mundo. Resgatam-se os lações da benignidade entre os seres humanos, aproximando o "EU" e este ideal de um "amigo", o qual se exterioriza no momento em que conhece como a ti próprio, com suas atribuições e atitudes com o meio exterior $^{31}$. É a partir dessa tensão, desse diálogo entre seres incompletos que se torna possível entender quais e porque se insiste, historicamente, nos fundamentos críticos dos Direitos Humanos.

$\mathrm{Na}$ medida em que se vivencia tempos líquidos, observa-se uma sociedade apoderada pelo consumismo, pela alienação da mídia e das redes, individualidade, desequilíbrio ecológico, conflitos étnicos e estereótipos de beleza, esses flagelos que assolam a coletividade, e acabam por modificar seus valores, compadece a sensibilidade dos indivíduos, consigo mesmo e com o próximo.

A Amizade, entendida como uma virtude, é necessária à vida, embora a sua constituição seja por motivada por interesses, prazer e utilidade. Nesse caso, é interessante rememorar as palavras de Sêneca (2002, p. 42) se torna oportuna: "[...] Se me derem sabedoria com a condição que eu a guarde para mim sem poder transmiti-la, eu a recusarei. Não é agradável possuir um bem quando não podemos dividi-lo".

No entanto, rememora Aristóteles ${ }^{32}$, que uma Amizade movida por interesse não é digna de ser considerada verdadeira, não obstante, torna-se factível e presente,

31 "A proximidade entre o 'Eu' e o (pretenso) amigo se des-vela na medida em que o conheces como a ti próprio. É ideal uma vida, rememora Sêneca, em que se possam partilhar segredos íntimos com todos, inclusive os inimigos. Entretanto, essa via nem sempre é possível. Esse é o fundamento necessário de se ter e confiar nos amigos". AQUINO, Sérgio Ricardo Fernandes de. Fronteiras planetárias: a busca da raciovitalidade amistosa e sustentável para a sociedade-mundo. Revista Novos Estudos Jurídicos, v. 19, n. 2, jul. 2014a, p. 438. Disponível em: <http://siaiap32.univali.br/seer/index.php/nej/article/view/6014/3290>. Acesso em: 30 set. 2016.

32 "[...] Os amigos cuja afeição é baseada no interesse não amam um ao outro por si mesmos, e sim por causa de algum proveito que obtêm um do outro. O mesmo raciocínio se aplica àqueles que se amam por causa do prazer; não é por seu caráter que gostamos das pessoas espirituosas, mas 
FERNANDES DE AQUINO, Sérgio Ricardo; DOS SANTOS, Wagner; FICAGNA, Victoria. Ética, moral e amizade em tempos líquidos: fundamentos críticos para uma práxis de direitos humanos. Revista Eletrônica Direito e Política, Programa de Pós-Graduação Stricto Sensu em Ciência Jurídica da UNIVALI, Itajaí, v.14, n.1, $1^{\circ}$ quadrimestre de 2019. Disponível em: www.univali.br/direitoepolitica - ISSN 1980-7791

afinal, por não ser um vínculo unipessoal - a Amizade -, evidencia e ocupa-se da relação com o outro, com as diferenças, trocas de convicções e ideais, sendo o indivíduo, útil ou agradável ao próximo.

Os nexos de Amizade, denotam traços de ramificações, isto é, a necessidade de vínculos interpessoais, voltados ao bem comum, disseminam a organização e interação social, levando em consideração uma pluralidade de conhecimento, cultura e nuances. Nessa linha de pensamento, fomenta-se a destreza para lidar com experiências cotidianas, na qual se faz presente a virtude Amizade. Esse companheirismo, a troca de sabedoria, os meios de compartilhamentos e fusão axiológicas, viabilizam condições sustentáveis de uma vida sadia. Reitera-se a constituição de novos paradigmas, como o Direito Fraterno ${ }^{33}$, pois, segundo Resta ${ }^{34}$ :

A Amizade é a forma mais significativa de uma comunidade possível que vive à espera de reconhecimentos, mas que também vive independentemente deles. E é a comunidade que não diferencia a pertença com base nos bens, mas que identifica formas complexas de identidade.

A questão da Fraternidade ${ }^{35}$ está intrinsecamente conexa com a Amizade, pois engloba não somente o ligame antropológico de um ser humano, mas sim de uma

porque as achamos agradáveis. Logo, as pessoas que amam as outras por interesse amam por causa do que é bom para si mesmas, e aquelas que amam por causa do prazer amam por causa do que lhes é agradável, e não porque a outra pessoa é a pessoa que amam, mas porque ela é útil ou agradável. Sendo assim, as Amizades deste tipo são acidentais, pois não é por ser quem ela é que a pessoa é amada, mas por proporcionar à outra algum proveito ou prazer". ARISTÓTELES, Ética a Nicômacos. par. 1156 a.

33"A Amizade, [...], não nasce, apenas, de uma escolha racional, mas se origina, também, dos nossos instintos. As pessoas procuram conviver e não se isolar. Na medida em que estabelecem vínculos amistosos, cria-se um ambiente fértil para as relações humanas e a produção do conhecimento". AQUINO, Sérgio Ricardo Fernandes de. Fronteiras planetárias: a busca da raciovitalidade amistosa e sustentável para a sociedade-mundo. Revista Novos Estudos Jurídicos. p. 440.

34 RESTA, Eligio. O Direito Fraterno. Tradução de Sandra Regina Martini Vial. Santa Cruz do Sul, (RS): Editora da EDUNISC, 2004, p. 23.

35 "A Fraternidade, sob o ângulo da Política, demonstra esse pacto de todos com todos no sentido de se mitigar as posturas egoístas e, movidos pela Amizade, elabora-se uma vida digna a partir das adversidades as quais insistem em segregar, destruir toda vontade em modificar um cenário mundial insustentável para outro possível, desejável. Observa-se, sim, uma postura pedagógica em tanta violência - simbólica, física ou psicológica - praticada contra as pessoas e o próprio mundo: rememorar o que é indispensável para a vida se manifestar, de todas as formas, indefinidamente neste Planeta". AQUINO, Sérgio Ricardo Fernandes de. Cidadania: por uma philia 
FERNANDES DE AQUINO, Sérgio Ricardo; DOS SANTOS, Wagner; FICAGNA, Victoria. Ética, moral e amizade em tempos líquidos: fundamentos críticos para uma práxis de direitos humanos. Revista Eletrônica Direito e Política, Programa de Pós-Graduação Stricto Sensu em Ciência Jurídica da UNIVALI, Itajaí, v.14, n.1, $1^{\circ}$ quadrimestre de 2019. Disponível em: www.univali.br/direitoepolitica - ISSN 1980-7791

coletividade, que ultrapassa fronteiras, totalizando todos os seres vivos que habitam a Terra ${ }^{36}$, pois desde o nosso nascimento, se estabelecerá ligações com o ventre materno, com a troca de favores, questões de necessidades, dar e retribuir, assim, todos os dias, em quaisquer situações que ocorram, estamos desenvolvendo elos no qual, a Amizade tornar-se-á núcleo propiciador de afetos, bondade, generosidade para um fidedigno estar-junto no mundo. ${ }^{37}$

Retomando a ideia de Aristóteles, em "A Ética a Nicômacos" sendo a Amizade, uma forma de excelência moral e extremamente necessária, à vivencia humana, ninguém deseja viver sem ter um vínculo, e sem ter um amigo, uma pessoa na qual possa dispor de sua Amizade e de um amparo que o ajude a enfrentar as controvérsias e desarmonias que cotidianamente sucede-se na convivência humana. Para que haja uma verdadeira Amizade, é importante a reciprocidade (axiológica) entre as pessoas, ou seja, insiste-se numa boa vontade de cooperar no intento de aspirar o bem comum a todos, não obstante se reconheça, muitas vezes, as dificuldades originárias de culturas não propensas ao diálogo e transformações. Nessa linha de pensamento, Aristóteles ${ }^{38}$ sinaliza:

[...] Mesmo quando viajamos para outras terras, podemos observar a existência generalizada de uma afinidade e afeição naturais entre as pessoas. A Amizade parece também manter as cidades unidas, e parece que os legisladores se preocupam mais com ela do que com a justiça; efetivamente, a concórdia parece assemelhar-se à Amizade, e eles procuram assegurála mais que tudo, ao mesmo tempo em que repelem tanto

democrática e fraterna. In: CUNHA, Paulo Jorge Fonseca Ferreira da; AQUINO, Sérgio Ricardo Fernandes de. Palimpsesto: a democracia. Rio de Janeiro: Lúmen Juris, 2016, p. 32.

36 Novamente, Sêneca destaca: "[...] Perguntas-me, escreve ele, que progresso eu fiz? Tornei-me meu amigo. Grande Progresso! Nunca mais estará só. Saibas que se tiveres semelhante amigo, terás o gênero humano por amigo". SÊNECA. As relações humanas: a Amizade, os livros, a filosofia, o sábio e a atitude perante a morte. Tradução de Renata Maria Parreira Cordeiro. São Paulo: Landy, 2002, p. 43.

37 Por outro lado, longe de apagar as diferenças, a fraternidade tematiza a comunhão de pactos entre sujeitos concretos com as suas histórias e as suas diferenças específicas, não com os poderes e as rendas de posições que escondem o egoísmo através da abstração. Para Resta, "[...] a vida será sempre excedente em relação ao Direito, e um bom modelo de convivência jurídica deve evitar colonizar sempre, e a toda custa, a intimidade, deixando espaço à soberania de cada um sobre si mesmo: não a soberania centralizante de um Estado, de uma maioria, de um poder de governo, mas aquela dissipada de cada um sobre a própria vida". RESTA, Eligio. O Direito Fraterno. p. 16.

38 ARISTÓTELES, Ética a Nicômacos. par. 1155a. 
FERNANDES DE AQUINO, Sérgio Ricardo; DOS SANTOS, Wagner; FICAGNA, Victoria. Ética, moral e amizade em tempos líquidos: fundamentos críticos para uma práxis de direitos humanos. Revista Eletrônica Direito e Política, Programa de Pós-Graduação Stricto Sensu em Ciência Jurídica da UNIVALI, Itajaí, v.14, n.1, $1^{\circ}$ quadrimestre de 2019. Disponível em: www.univali.br/direitoepolitica - ISSN 1980-7791

quanto possível o facciosismo, que é a inimizade nas cidades $[\ldots]$.

A semelhança em relação à excelência moral como forma do bem querer do seu companheiro de jornada - de seu amigo - é que se caracteriza a Amizade perfeita, ou seja, as pessoas que desejam o bem aos seus amigos, serão boas em si. Contribui-se, desse modo, para uma expressão de estar-junto, de alteridade e fraternidade, hoje, continuamente esquecido, ou ignorado, inclusive como vetor de aperfeiçoamento crítico dos Direitos Humanos, na qual as relações de reciprocidade se esvaem na medida em que se promove o bem. No entanto, ao momento em que essa "segurança e utilidade" acaba, a Amizade se torna apenas um objeto, um nome vazio de significado.

Quando o princípio da Amizade, e outros fundamentos axiológicos, são projetados como mero produto do pensamento abstrato, a sua prática no cenário social, não condiz com o seu real conteúdo e acepção. Devido ao desinteresse das pessoas no seu cotidiano, muitas vezes omisso e no qual os valores se tornam "invisíveis", a justiça, equidade, alteridade, os princípios e direitos pertencentes aos seres humanos, demonstram sua ineficiência e deforma despótica, não somente no âmbito jurídico, mas, sim, em diversos segmentos das relações sociais e individuais. Cria-se, diante desse cenário, um sentimento de injustiça pelo não cumprimento dos objetivos enunciados pelos valores ou pelas leis ${ }^{39}$.

Na medida em que se desprezam esses vetores integração humana, quando esses não são aplicados de forma coesa e pertinente, estimula-se um certo distanciamento das pessoas em estabelecer vínculos umas com as outras. Consequentemente, os indivíduos perdem o interesse em buscar a efetiva realização de seus direitos, garantias, aspirações, ou seja, deixam de desenvolver,

\footnotetext{
39 "Na verdade, a Política do Direito entende que não é qualquer conteúdo que possa animar uma norma jurídica. Tal conteúdo deve conformar-se com os valores inerentes aos princípios gerais do Direito, os quais, por sua vez, devem sintonizar-se com os direitos fundamentais do ser humano, dentre eles o direito de ser tratado com respeito e dignidade pelos agentes do Estado. $\mathrm{O}$ engodo e a falácia escondidos numa norma (mesmo constitucional), impedem a sua validade material, e consequentemente sua eficácia". MELO, Osvaldo Ferreira de. Temas atuais de política do direito. Porto Alegre: Sergio Antônio Fabris, 1998, p. 57.
} 
FERNANDES DE AQUINO, Sérgio Ricardo; DOS SANTOS, Wagner; FICAGNA, Victoria. Ética, moral e amizade em tempos líquidos: fundamentos críticos para uma práxis de direitos humanos. Revista Eletrônica Direito e Política, Programa de Pós-Graduação Stricto Sensu em Ciência Jurídica da UNIVALI, Itajaí, v.14, n.1, $1^{\circ}$ quadrimestre de 2019. Disponível em: www.univali.br/direitoepolitica - ISSN 1980-7791

deixam de promover - numa perspectiva realista40 - a humanização da humanidade como resultado do aperfeiçoamento dos Direitos Humanos, fator no qual expressa as principais transformações civilizacionais no mundo.

Nessa linha de pensamento, verifica-se a necessidade de se refletir sobre a importância da dimensão social, de como a socialidade é indispensável para fomentar uma perspectiva de bem-comum, de Direito Fraterno, no qual institui-se o equilíbrio, a alteridade a fraternidade e um juízo de convivência. Para que haja o cumprimento dessa afirmação, o princípio da Amizade é de extremo proveito, e deve ser empregado como práxis no cotidiano dos povos ${ }^{41}$.

A participação mútua das pessoas, a cooperação para a manutenção da convivência humana, aceita a multiplicidade de realidades que abrangem os povos. Reputar cada indivíduo como possibilidade de práticas reiteradas ao progresso harmônico da ordem social, favorece a necessidade de Direitos Humanos fundados num Direito Fraterno. Nesse caso, a concepção da união das pessoas para estruturar um futuro digno no mundo, bem como no cuidado às gerações que estão a vir, favorece o surgimento de atitudes para se consolidar vínculos amistosos e morais comuns.

Num futuro não distante, a Amizade tornar-se-á, além de uma ideologia aspirante, uma transformação, onde todos os seres humanos, usufruindo de forma digna e sadia de sua virtude - Amizade - estabelece-se a união para alcançar êxito em suas conquistas, além da felicidade e a justiça do bem-comum, do estar-junto no mundo, se verificará de forma plena a todos.

\footnotetext{
40 "[...] Partimos, então, do reconhecimento de nossa capacidade humana de fazer e desfazer os mundos que nos são dados. Com isso, assumimos uma visão estritamente 'real' da realidade, pois somos conscientes das quebras, fissuras e porosidades do mundo em que vivemos. Logo, realista significa saber onde estamos e propor caminhos para onde ir. Ser realista exige, portanto, apostar na construção de condições materiais que permitam uma vida digna de ser vivida". HERRERA FLORES, Joaquín. A (re)invenção dos direitos humanos. Tradução de Carlos Roberto Diogo Garcia et al. Florianópolis: Fundação Boiteux, 2009, p. 61/62.

${ }^{41}$ Assim, faz-se necessário pensar o direito em relação à civitas máximas e não às pequenas pátrias dos Estados. O esforço, aqui, é pôr em evidência a angústia dos confins estatais, de forma a abrir espaço para a reflexão acerca dos Direitos Humanos, com uma consciência a mais: "[...] a de que a humanidade é simplesmente o lugar comum, somente em cujo interior pode-se pensar o reconhecimento e a tutela". RESTA, Eligio. O Direito Fraterno. p. 12.
} 
FERNANDES DE AQUINO, Sérgio Ricardo; DOS SANTOS, Wagner; FICAGNA, Victoria. Ética, moral e amizade em tempos líquidos: fundamentos críticos para uma práxis de direitos humanos. Revista Eletrônica Direito e Política, Programa de Pós-Graduação Stricto Sensu em Ciência Jurídica da UNIVALI, Itajaí, v.14, n.1, $1^{\circ}$ quadrimestre de 2019. Disponível em: www.univali.br/direitoepolitica - ISSN 1980-7791

\section{CONSIDERAÇÕES FINAIS}

No diálogo entre Ética, Moral e Amizade percebe-se a discrepância e o detrimento de princípios na era atual, os quais, antigamente, ou até mesmo, ante as suas metamorfoses, se honrava e se dispunha de respeito. Nessa linha de pensamento, reitera-se as concepções de Zygmunt Bauman, no qual, vive-se em tempos líquidos, ou seja, nada é feito para durar. No entanto, embora sejam perspectivas justificadas, torna-se de extrema relevância buscar o entendimento e possíveis respostas dessas transformações, porém não apenas ao mundo, ao convívio ao nosso redor, e, sim, como chance de nosso autoconhecimento e autocrítica.

Cada ser humano reconhece e compreende uma igualdade a qual gera respeito e responsabilidades mútuas. Para que hajam novos cenários, utopias e esperanças, demanda-se, sim, interrogações a sobre novos paradigmas, princípios, ideais, e também o porquê, lamentavelmente, desta ruína axiológica provocada pelos tempos líquidos.

Os debates acerca deste tema englobam questões éticas, morais, jurídicas, e principalmente, a Amizade como a possibilidade de fusão dos vínculos harmoniosos, justos, socialmente úteis e de reiterada aprendizagem para se conquistar, permanentemente, nossa humanização. No entanto, a falta de ações éticas e morais dos indivíduos em diversas situações do cotidiano, no trabalho, na família, na relação com o próximo, afasta de si o bem e o liame que os liga com o mundo, pois somos seres de interligados, seja com nossos semelhantes ou o mundo. Ao momento em que se perde um elo como a Amizade, a moralidade, a fraternidade e a postura ética qualquer forma de convivência se torna tão somente um fenômeno desprovido de significado existencial.

Esse é o mundo e a vida: um quebra-cabeças, uma máquina, cuja falta de peças ou de engrenagens não permite o seu funcionamento, pois cada um, com sua contribuição, cumpre seu papel para se constituir uma vida mais harmoniza. Esse é o cenário que se espera dos feitos humanos, em outras palavras, que suas ações sejam voltadas a rememorar os ensinamentos de Amizade com o próximo que ainda há tempos remotos, foram deixados, contribuir para uma vivência de paz 
FERNANDES DE AQUINO, Sérgio Ricardo; DOS SANTOS, Wagner; FICAGNA, Victoria. Ética, moral e amizade em tempos líquidos: fundamentos críticos para uma práxis de direitos humanos. Revista Eletrônica Direito e Política, Programa de Pós-Graduação Stricto Sensu em Ciência Jurídica da UNIVALI, Itajaí, v.14, n.1, $1^{\circ}$ quadrimestre de 2019. Disponível em: www.univali.br/direitoepolitica - ISSN 1980-7791

com o outro e exercendo a cidadania de forma a deixar um legado de bondade que se instale no futuro.

Não se pode levar em consideração apenas as lentes escuras de um individualismo irresponsável, no qual apenas a falta de ética, a imoralidade, e os vínculos perdidos se manifestam. É necessário usar destas circunstancias para fazer com que floresça uma nova estação, novas ramificações e novas folhas, onde se possa construir um ambiente novo, bem como se espera em cada ano, da troca de estações, ou seja, cada dia, cada semana, mês e ano, conforme as mudanças ocorrem. É necessário, também, se adaptar às transformações, porém, sempre se adequando de forma a que possa acrescentar por meio de suas próprias virtudes, as quais ganham novos sentidos na medida em que as relações humanas se tornam mais complexas.

Diante das alterações que se manifestam no mundo, e cuja influencia direta aparece na interpretação e práxis dos Direitos Humanos, verifica-se como as questões de aprendizagens educacionais, as avançadas tecnologias, as transações de informações, o multiculturalismo e mesmo as metamorfoses que ocorrem no interior das subjetividades, não como se negar a força dessas categorias como expressões de um genuíno estar-junto-com-o-Outro-no-Mundo.

Na questão dos Direitos Humanos, a propósito, as inovações e alterações são constantes, o que antes não o era considerado objeto de proteção, hoje o é, a exemplo, do Direito dos Animais, dos Direitos da Natureza, dos Direitos das Crianças, Adolescentes e Idosos, entre outros. Muito embora as progressivas alterações não estejam explicitas, percebe-se, mais e mais, atitudes solidárias, cooperativas, cujo o respeito à Liberdade e Igualdade favorecem, na dimensão política e jurídica, o esclarecimento da Fraternidade e Amizade.

Nesse tempo líquido, é preciso adaptar-se com as diferenças, respeitar suas múltiplas facetas, persistir no autoconhecimento para, depois, compreender e aprender com o próximo, afinal, essas diferenças e o desnivelamento com o mundo ideal é a chave necessária para se descobrir qual é o ponto de partida para as mudanças que se quer a esse mundo desejável. 
FERNANDES DE AQUINO, Sérgio Ricardo; DOS SANTOS, Wagner; FICAGNA, Victoria. Ética, moral e amizade em tempos líquidos: fundamentos críticos para uma práxis de direitos humanos. Revista Eletrônica Direito e Política, Programa de Pós-Graduação Stricto Sensu em Ciência Jurídica da UNIVALI, Itajaí, v.14, n.1, $1^{\circ}$ quadrimestre de 2019. Disponível em: www.univali.br/direitoepolitica - ISSN 1980-7791

Para tanto, a fim de permanecer esses vínculos de Amizade, Fraternidade, Ética e Moralidade nos tempos líquidos, é indispensável que cada um resgate dentro de si, as suas virtudes, para, após, socializa-las junto com o próximo. Talvez, aqui, esteja o mistério, o sentido invisível de uma axiologia necessária para esse mundo líquido. Percebe-se, nessa afirmação, como a hipótese de pesquisa está confirmada no seu sentido negativo, ou seja, esses vetores axiológicos são necessários para a constituição das relações humanas e o aperfeiçoamento pragmático dos Direitos Humanos, não obstante o sentido efêmero deste tempo líquido.

Reitera-se que a integração humana, a partir de mecanismos de autoconhecimento e aprimoramento de atitudes, favorece a transformação axiológica do mundo, faz com que, com cautela, pequenos e vigorosos passos contribuem com o aprimoramento da Moral, como fundamento do agir ético, e da Amizade como preceito político de integração entre os povos.

Ao se reconhecer o Outro na sua (radical) diferença, nas suas limitações, atribuições, destreza e falhas, se reconhece o mundo como é, ou seja, identificase como se torna possível a convivência sem que haja apelo a atitudes fanáticas ou cínicas. Aos poucos, estimula-se a preservação da paz pela Amizade e Moral como pressupostos de manutenção da paz contra todas as formas de indiferença, de injustiça, de um individualismo irresponsável.

\section{REFERÊNCIAS DAS FONTES CITADAS}

AQUINO, Sérgio Ricardo Fernandes de. Cidadania: por uma philia democrática e fraterna. In: CUNHA, Paulo Jorge Fonseca Ferreira da; AQUINO, Sérgio Ricardo Fernandes de. Palimpsesto: a democracia. Rio de Janeiro: Lúmen Juris, 2016.

AQUINO, Sérgio Ricardo Fernandes de. Fronteiras planetárias: a busca da raciovitalidade amistosa e sustentável para a sociedade-mundo. Revista Novos Estudos Jurídicos, v. 19, n. 2, jul. 2014a. Disponível em: <http://siaiap32.univali.br/seer/index.php/nej/article/view/6014/3290>. Acesso em: 30 set. 2016.

AQUINO, Sergio Ricardo Fernandes de. 0 Direito em busca de sua humanidade: diálogos errantes. Curitiba: CRV, 2014b. 
FERNANDES DE AQUINO, Sérgio Ricardo; DOS SANTOS, Wagner; FICAGNA, Victoria. Ética, moral e amizade em tempos líquidos: fundamentos críticos para uma práxis de direitos humanos. Revista Eletrônica Direito e Política, Programa de Pós-Graduação Stricto Sensu em Ciência Jurídica da UNIVALI, Itajaí, v.14, n.1, $1^{\circ}$ quadrimestre de 2019. Disponível em: www.univali.br/direitoepolitica - ISSN 1980-7791

AQUINO, Sérgio Ricardo Fernandes de; GRUBBA, Leilane Serratine. Direitos Humanos: o problema do contexto/Human Rights: the problem of context. Revista Direito e Política, Itajaí, v. 10, n. 3, p. 1964-1989, 2015. ISSN 1980-7791.

<https://siaiap32.univali.br/seer/index.php/rdp/article/view/8027/4575>.

Acesso em: 20 ago. 2017.

ARISTÓTELES, Ética a Nicômacos. Tradução de Mário da Gama Kury. 4. ed. Brasília: Editora Universidade de Brasília, 2001.

BAUMAN, Zygmunt. A vida em fragmentos: sobre a ética pós-moderna. Tradução de Alexandre Werneck. Rio de Janeiro: Jorge Zahar, 2011.

BAUMAN, Zygmunt. Ética pós-moderna. Tradução: João Rezende Costa, São Paulo: Paulus, 1997.

BAUMAN, Zygmunt. Modernidade e holocausto. Tradução de Marcus Penchel. Rio de Janeiro: Zahar, 1998.

BAUMAN, Zygmunt. Modernidade líquida. Tradução de Plínio Dentzien. Rio de Janeiro: Zahar, 2001.

BAUMAN, Zygmunt. Tempos líquidos. Tradução de Carlos Alberto Medeiros, Rio de Janeiro: Jorge Zahar, 2007.

BITTAR, Eduardo C. B. O direito na pós-modernidade: e reflexões frankfurtianas. 2. ed. Rio de Janeiro: Forense Universitária, 2009.

BLOCH, Ernst. O princípio esperança. Tradução de Nélio Schneider. Rio de Janeiro: EdUERJ/Contraponto, 2005, v.1.

CORTINA, Adela. Ética sem moral. Tradução de Marcos Marcionilo. São Paulo: Martins Martins Fontes, 2010.

HERRERA FLORES, Joaquín. A (re)invenção dos direitos humanos. Tradução de Carlos Roberto Diogo Garcia et al. Florianópolis: Fundação Boiteux, 2009.

JULLIEN, François. O diálogo entre as culturas: do universalismo ao multiculturalismo. Tradução de André Telles. Rio de Janeiro: Zahar, 2009.

KANT, Immanuel. Crítica da razão pura. Tradução de Fernando Costa Mattos. Bragança Paulista, (SP); Petrópolis, (RJ): Editora Universitária São Francisco/Vozes, 2012.

MAFFESOLI, Michel. No fundo das aparências. Tradução de Bertha Halpern Gurovitz. 3. ed. Petrópolis, (RJ): Vozes, 2005.

MELO, Osvaldo Ferreira de. Temas atuais de política do direito. Porto Alegre: Sergio Antônio Fabris, 1998. 
FERNANDES DE AQUINO, Sérgio Ricardo; DOS SANTOS, Wagner; FICAGNA, Victoria. Ética, moral e amizade em tempos líquidos: fundamentos críticos para uma práxis de direitos humanos. Revista Eletrônica Direito e Política, Programa de Pós-Graduação Stricto Sensu em Ciência Jurídica da UNIVALI, Itajaí, v.14, n.1, $1^{\circ}$ quadrimestre de 2019. Disponível em: www.univali.br/direitoepolitica - ISSN 1980-7791

MORIN, Edgar. 0 método 6: Ética. Tradução de Juremir Machado da Silva. 3.ed. Porto Alegre: Sulina, 2007.

PASOLD, Cesar Luiz. Metodologia da pesquisa jurídica: teoria e prática. 13. ed. Florianópolis: Conceito Editorial, 2015.

PIRES, Cecília. Leituras filosóficas passadas a limpo: temas e argumentos. Passo Fundo, (RS): IFIBE, 2016.

RESTA, Eligio. O Direito Fraterno. Tradução de Sandra Regina Martini Vial. Santa Cruz do Sul, (RS): Editora da EDUNISC, 2004.

SÊNECA. As relações humanas: a Amizade, os livros, a filosofia, o sábio e a atitude perante a morte. Tradução de Renata Maria Parreira Cordeiro. São Paulo: Landy, 2002.

SOARES, Josemar Sidinei; CHIARA LOCCHI, Maria. O papel do indivíduo na construção da dignidade da pessoa humana/ The individual role in the construction of the human person dignity. Revista Brasileira de Direito, Passo Fundo, v. 12, n. 1 , p. 31-41, jun. 2016. ISSN 2238-0604. Disponível em: <https://seer.imed.edu.br/index.php/revistadedireito/article/view/1118/835>. Acesso em: 20 ago. 2017.

SPAREMBERGER, Raquel Fabiana; GABRIEL, José Elias. Multiculturalismo de negação: um olhar para a realidade da prisão da mulher estrangeira/Multiculturalismo of negativo: a look at the reality of foreign's women prison. Revista Videre, Dourados, v. 9, n. 17, p. 139-155, jan./jul. 2017. ISSN 2177-7837. Disponível em: <http:// http://ojs.ufgd.edu.br/index.php/videre/article/view/6113>. Acesso em: 20 ago. 2017.

ZAMBAM, Neuro José; AQUINO, Sérgio Ricardo Fernandes de. Tolerância: reflexões filosóficas, políticas e jurídicas para o século XXI. Revista da AJURIS. Porto Alegre, v. 142, n. 137, março de 2015. Disponível em: http://www.ajuris.org.br/OJS2/index.php/REVAJURIS/article/view/389/323.

Acesso em 19 de jul. de 2016.

RECEBIDO EM: 05/02/2019

APROVADO EM: 10/04/2019 